\title{
ПЕДАГОГИЧЕСКАЯ ТЕХНОЛОГИЯ КОНСТРУИРОВАНИЯ УЧЕБНОГО ПРОЦЕССА
}

\author{
Юзликаев Ф. Р., доктор педагогических наук, профессор \\ Ташкентский государственный педагогический университет, Узбекистан
}

DOI: https://doi.org/10.31435/rsglobal_ijitss/31082019/6617

\section{ARTICLE INFO}

Received 12 June 2019

Accepted 19 August 2019

Published 31 August 2019

\section{KEYWORDS}

information map, design of the educational process, training model, pedagogical process, pedagogical technology, technological map, technological approach, educational technology.

\begin{abstract}
The article is devoted to the educational technology design of the educational process. According to the author, the technology of designing the pedagogical process cannot be reduced only to thinking of the teacher's actions, maintenance and use of pedagogical tools, but should be carried out with a focus on students, a group of schoolchildren and each individual.
\end{abstract}

Citation: Юзликаев Ф. Р. (2019) Pedagogicheskaya Tekhnologiya Konstruirovaniya Uchebnogo Processa. International Journal of Innovative Technologies in Social Science. 5(17). doi: 10.31435/rsglobal_ijitss/31082019/6617

Copyright: (C) 2019 Юзликаев Ф. Р. This is an open-access article distributed under the terms of the Creative Commons Attribution License (CC BY). The use, distribution or reproduction in other forums is permitted, provided the original author(s) or licensor are credited and that the original publication in this journal is cited, in accordance with accepted academic practice. No use, distribution or reproduction is permitted which does not comply with these terms.

С точки зрения философии, технология представляет собой сложную развивающуюся систему артефактов, производственных операций и процессов, ресурсных источников, подсистем социальных последствий информации, управления, финансирования и взаимодействия с другими системами.

В методической литературе нет общепринятого понятия педагогической технологии. Часто под педагогической технологией понимают последовательную взаимосвязанную систему действий педагога, направленную на решение педагогических задач, или планомерное последовательное воплощение на практике заранее спроектированного педагогического процесса.

В.В. Гузеев определяет образовательную технологию как «...комплекс, состоящий из некоторого представления планируемых результатов обучения, средств диагностики текущего состояния обучаемых, набора моделей обучения, критериев выбора оптимальной модели для данных конкретных условий» [2, с.45].

Приведём определение педагогической технологии, данное В.М. Монаховым: «Педагогическая технология есть область исследования теории и практики (в рамках системы образования), имеющая связь со всеми сторонами организации педагогической системы для достижения специфических и потенциально воспроизводимых педагогических результатов» [3, с. 78-85].

Педагогическая энциклопедия трактует понятие педагогической технологии как совокупности средств и методов воспроизведения теоретически обоснованных процессов обучения и воспитания, позволяющих успешно реализовать поставленные образовательные цели. Педагогическая технология предполагает соответствующее научное конструирование, при котором эти цели задаются достаточно однозначно, и сохраняется возможность объективных поэтапных измерений и итоговой оценки достигнутых результатов. 
В своих трудах В.П. Беспалько определяет следующую последовательность моделирования педагогической системы: системы;

1. определение цели, подробное описание задач функционирования педагогической

2. описание содержания обучения и воспитания с учетом требований к подготовке выпускника и общедидактических требований, таких как последовательность, доступность, научность, неизбыточность, наглядность;

3. выбор и разработка дидактических процессов;

4. определение организационных форм обучения [1, с.56-62].

Академик В.M. Монахов называет следующие критерии технологичности: концептуальность, системность, управляемость, эффективность, воспроизводимость [3, с.17-99].

Следовательно, технологический подход - это радикальное обновление инструментальных и методологических средств педагогики и методики при условии сохранения преемственности в развитии педагогической науки и практики.

Конструирование учебного процесса целесообразно проводить в шесть этапов:

1. Конструирование системы микроцелей, задающих границы рабочего поля будущего учебного процесса. Микроцель - краткая запись основных знаний и умений, которыми должны овладеть ученики.

2. Перевод содержания образовательного стандарта на «язык» деятельности учащегося, т.е. определение содержания диагностики. Диагностика - система заданий по проверке усвоенных знаний; система заданий, позволяющая установить факт достижения или не достижения микроцели. Для каждой микроцели - своя диагностика.

В.М. Монахов выделяет ряд правил, которые необходимо соблюдать при составлении диагностики:

- стандартная диагностика имеет четыре задания: два на уровне требований к обязательному минимуму, два - на повышенном уровне;

- общий вид диагностики:

$\checkmark$ задание на уровне требований стандарта;

$\checkmark$ задание на уровне требований стандарта;

$\checkmark$ задание на уровне требований к оценке «хорошо»;

$\checkmark$ задание на уровне «отлично» [3, с. 115].

3. Выбор траектории движения учащегося к микроцели, что выражается в выборе объема и содержания самостоятельной деятельности учащихся. Дозирование самостоятельной деятельности учащихся представляет собой совокупность заданий, которые учащийся должен выполнить самостоятельно.

4. Определение логической структуры модели учебного процесса в границах учебной темы. Структура - это цепочка уроков, разбитых по числу микроцелей. Каждая микроцель предполагает некую группу уроков, на которых, во-первых, должна быть достигнута микроцель, во-вторых, это зона ближайшего развития учащегося.

5. Составление технологической карты учебной темы как взаимосвязанной системы параметров модели учебного процесса (логической структуры темы, целеполагания, диагностики, коррекции и дозирования материала).

6. Конкретизация замысла проекта в виде совокупности информационных карт урока.

По каждой теме проект учебного процесса должен состоять из Технологической карты и набора Информационных карт урока. Информационная карта включает в себя: содержание учебно-познавательной деятельности учащегося, методический инструментарий учителя, результаты взаимодействия учитель - ученик.

Конструирование учебного процесса по педагогике базируется на двух началах Государственный образовательный стандарт (ГОС) в виде требований, которые он налагает, и логика технологического подхода. ГОС определяет содержание и основные требования к подготовке учащихся, технология - логическую структуру курса.

Первый этап - это определение целей. Можно выделить цели разного уровня. Глобальные цели обучения педагогике в колледже - это овладение системой педагогических знаний и умений, необходимых для применения в практической деятельности, изучения смежных дисциплин, продолжения образования; интеллектуальное развитие, формирование 
качеств личности, необходимых человеку для полноценной жизни в современном обществе: ясность и точность мысли, критичность мышления, интуиция, логическое мышление, элементы алгоритмической культуры, пространственных представлений, способность к преодолению трудностей; формирование представлений об идеях и методах педагогики математики, средства моделирования явлений и процессов; воспитание культуры личности, отношения к педагогике как к части общечеловеческой культуры, понимание значимости педагогики для научнотехнического прогресса.

Создавая проект курса педагогики нужно помнить, что основная цель - это не только передача знаний, и формирование навыков, а всестороннее развитие личности учащегося, подготовка его к профессиональной деятельности, адаптации в обществе.

Далее необходимо определить цели непосредственно педагогического образования, составить систему микроцелей по каждой учебной теме. Но прежде, чем перейти к формулировке этого уровня целеполагания, необходимо определить рамки учебной темы. Для этого вновь обращаемся к стандарту и формулируем темы, исходя из требований к обязательному минимуму содержания образовательных программ. Необходимо отметить, что определение рамок темы не канонизируется, и нередко при формулировке системы микроцелей, появляются предпосылки для изменения этих рамок. Такие изменения не влекут за собой нарушения логики технологии и отклонения от стандарта, являются следствием творческого подхода к конструированию. Главное, чтобы весь материал находил своё отражение в учебных темах.

После формулировки всех учебных тем, переходим к выделению микроцелей, помня о том, что они должны быть диагностируемы и являться следствием общих целей обучения педагогики. После того, как будут сформулированы все микроцели курса, требуется осуществить их общий анализ. Необходимо, чтобы совокупность микроцелей полностью отражала требования стандарта.

Следующий этап конструирования - перевод содержания образовательного стандарта на «язык» деятельности учащегося, т.е. определение содержания диагностики. На этом этапе каждой микроцели ставим в соответствие четыре диагностические задачи, две из которых отражают уровень стандарта (обязательный минимум), одна соответствует оценке - «хорошо», и одна - «отлично». Важно, чтобы задания не только выявляли уровень знаний учащегося, но и уровень развития логического и пространственного мышления, владения чёткой речью педагога. В этой связи особо хочется обратить внимание на то, что диагностику по педагогике не следует осуществлять в форме тестирования.

Далее определены траектории движения учащегося к микроцели, что выражается в выборе объёма и содержания самостоятельной деятельности учащихся. Необходимо выбрать такие задания для домашней работы учащегося, чтобы их грамотное выполнение гарантировало решение диагностических задач. Благодаря трехступенчатой структуре домашнего задания, учащиеся самостоятельно смогли определить уровни своих знаний. При выборе заданий для самостоятельной работы по педагогике, важно включать задачи разных типов.

После этого определяется логическая структура и составляется технологическая карта учебной темы, в которой отражены все блоки конструирования, в том числе блок диагностики, в рамках которого прогнозируются затруднения и типичные ошибки учащихся при изучении данной темы.

Таким образом, общая схема конструирования будет иметь следующий вид (Рис. 1.)

Таблица 1. Структура конструирования курса педагогики.

\begin{tabular}{|l|l|l|}
\hline \multicolumn{2}{|c|}{ Логическая структура } \\
\hline Целеполагание & Диагностика & Коррекция \\
\hline Дозирование самостоятельной деятельности & \\
\hline
\end{tabular}

Проведенный эксперимент в Ташкентском педагогическом колледже на 2 курсе по внедрению разработанной технологии конструирования показал, что использование педагогической технологии значительно повышает показатели успеваемости учащихся: рейтинговые баллы по каждой диагностической работе в экспериментальной группе значительно выше, большее число учащихся достигает не только стандарта, но уровней «хорошо» и «отлично». 


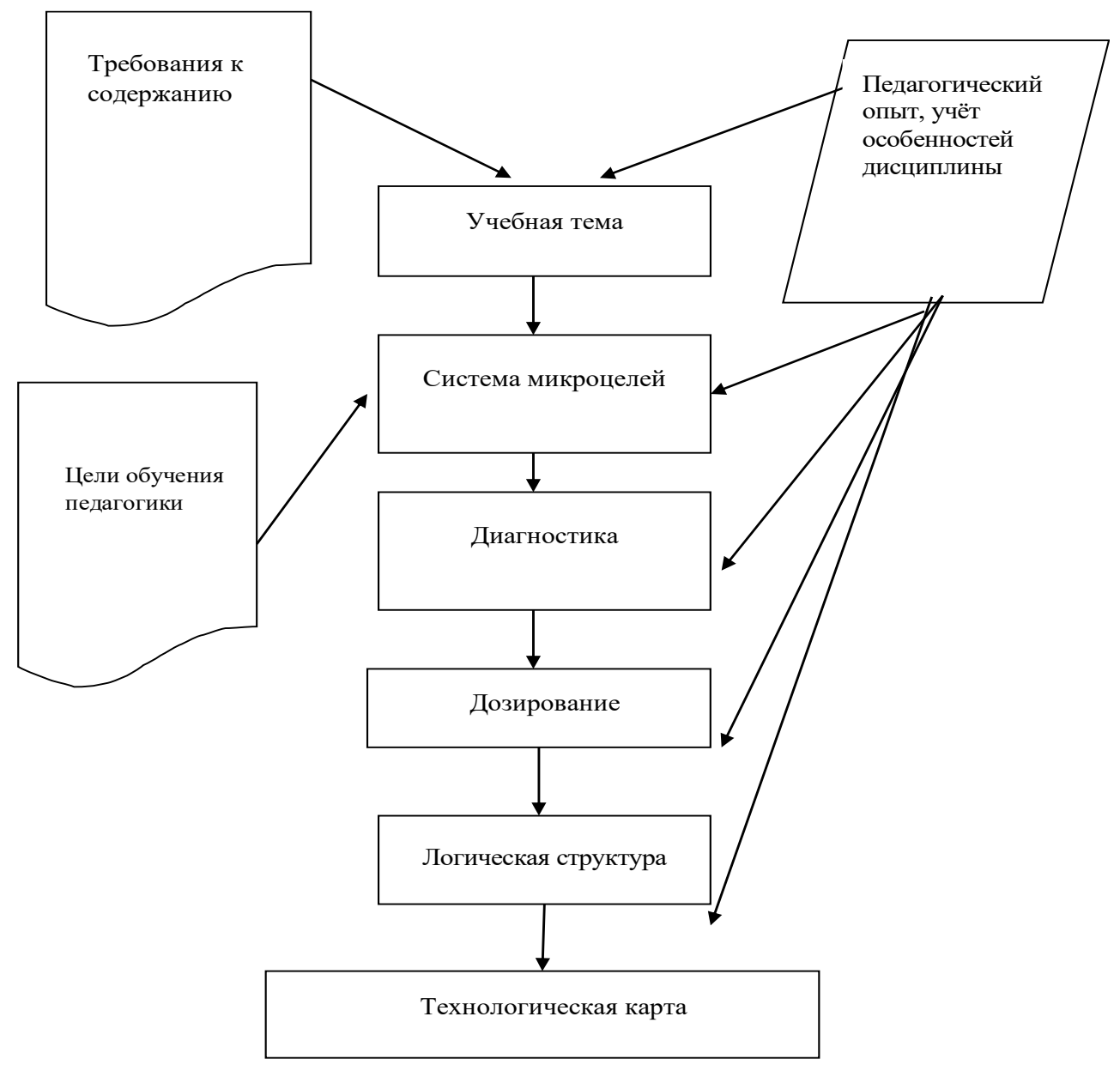

Puc. 1.

Таким образом, превалирующие число учащихся в экспериментальной группы (14 человек) справляется с диагностическими заданиями успешнее учащихся контрольной группы (12 человек).

Результаты педагогического эксперимента по технологии конструирования и осуществления педагогического процесса у обучающихся в педагогическом колледже (14 человек в экспериментальной группе) и (12 человек в контрольной группе)

Таблица 2.

\begin{tabular}{|l|l|l|}
\hline \multirow{2}{*}{ Уровень } & 2 курс \\
\cline { 2 - 3 } & Экспериментальная группа & Контрольная группа \\
\hline Высокий & $31 \%$ & $28 \%$ \\
\hline Средний & $44 \%$ & $45 \%$ \\
\hline Низкий & $25 \%$ & $27 \%$ \\
\hline
\end{tabular}

\section{Экспериментальная группа}

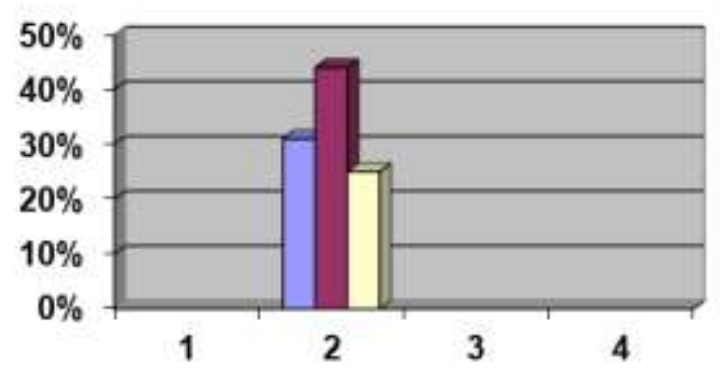

口Высокий
घСредний
वНизкий

Puc. 2. 


\section{Контрольная групnа}

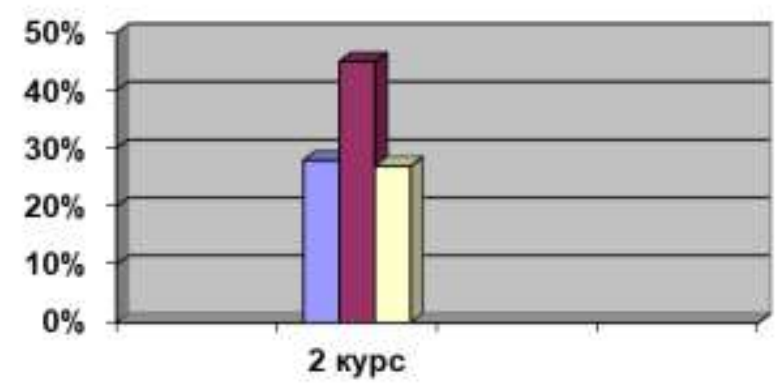

\section{口Высокии \\ чСредний \\ वНизкий}

Puc. 3.

В ходе исследования пришли к выводу, что анализ, прогноз и проект представляют неразрывную триаду при решении любой педагогической задачи вне зависимости от её предметно-содержательного наполнения и временных ограничений. Продуктивность решения стратегических, тактических и оперативных задач в равной мере обусловливается качеством технологии конструирования вне зависимости от того, был проект как её результат заранее зафиксирован на бумаге в форме плана (плана-конспекта, конспекта) или нет.

Технология конструирования педагогического процесса не может быть сведена к обдумыванию лишь действий педагога, содержания и возможностей использования педагогических средств. Она должна осуществляться с ориентацией на учащихся, группу школьников и каждого в отдельности. Другими словами, такая технология требует предположительного конструирования действий учащихся.

\section{ЛИТЕРАТУРА}

1. Беспалько В.П. Слагаемые педагогической технологии. - М.: Педагогика, 1999. -192c.

2. Гузеев В.В. Лекции по педагогической технологии. - М.: Знание, 1992. - 60c.

3. Монахов В.М. Технологические основы проектирования и конструирования учебного процесса: Монография. - Волгоград: Перемена, 1995. - 152c.

4. Седова Н.Е. Основы практической педагогики: Учебное пособие. - М.: ТЦ Сфера, 2008. -192 c.

5. Черных М.В. Педагогическая технология в модернизации образования: пять шагов к успеху. - М., 2003. $-58 \mathrm{c}$. 